BRIEF COM MUNICATON

\title{
Self made device by rural Nepalese women for pelvic organ prolapse worn for more than a decade: A constant source of vaginal discharge
}

\begin{abstract}
Complete disappearances of prolapse after the removal of the self made vaginal vaginal devices, made out of sand, jute and fruit seed residue worn for 17-30 years is presented here which speaks of uterovaginal prolapse as gynecological morbidity.
\end{abstract}

Key word: Gynecological morbidity and uterine prolapse.

\section{Practices in rural Nepal in yester years}

It's not surprising why women have major degree of uterovaginal prolapse in Nepal which is being recognized as health morbidity factor currently. Even today, a woman in her thirties and a multipara with six living children have been attended with complete procidentia; the uterine cervix fallen down up to her knees which was met in a recent Gynecological mobile health camp in Lamjung (Fig A).

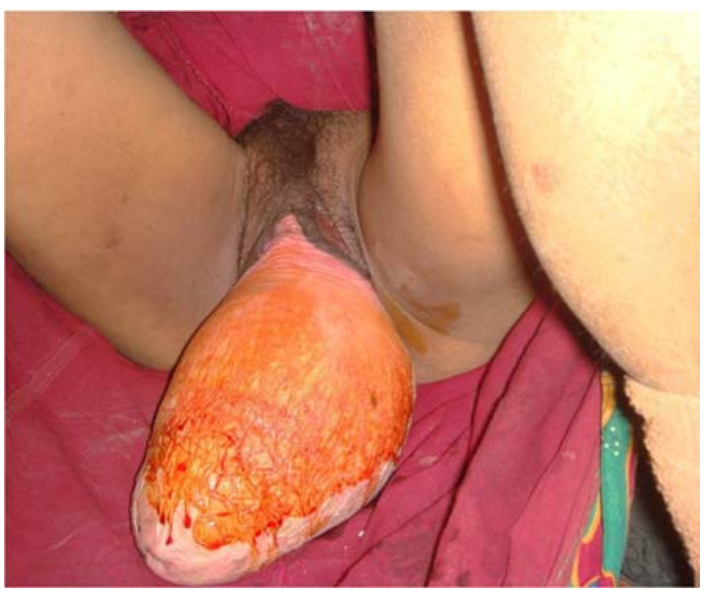

During one such surgical camp, many women who had been using created devices against prolapse and packed away the uterus for several years came across. Three such vaginal devices made by women themselves for the relief of the symptoms of pelvic organ prolapse are described.

The common factors in all these three cases were uterovaginal that followed home delivery and women looking for the remedy from the problems gave history of self insertion of homed made devices 17-30 years back which had converted into to stones generating foul smelly vaginal discharge.

All the three women were summoned due to foul smelling vaginal discharge after the removal of the impacted device was no longer were seen to have evidence of uterovaginal prolapse. (Table1)Similar description of cases was not seen Pub Med search.

\section{Comment}

Pelvic organ prolapse must have been a problem always, now they are getting recognized and operated in near village. Four groups of women with prolapse were seen. 

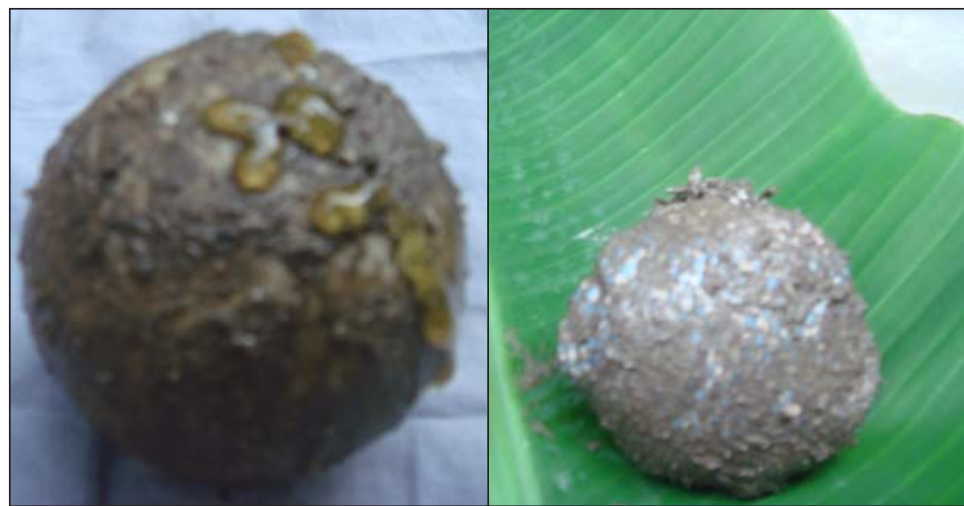

Case I:

Fig I. Colpolyth or a stone like material was found impacted in vagina. It was a sand bag.

\section{Case2}

Fig 2.

Waste product of sweat fruit seeds locally named as CHIURI(The pulp is eaten and oil is extracted from seeds).

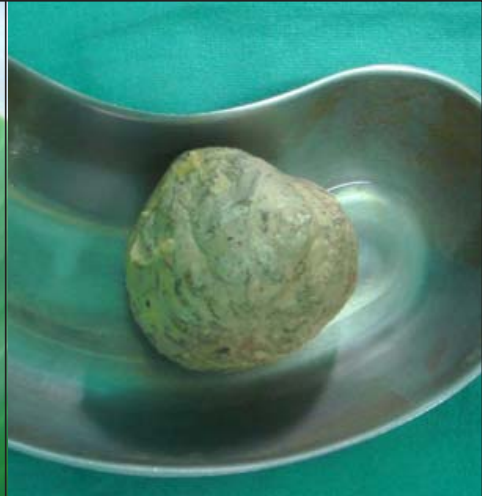

Case 3

Fig 3. Pieces of jute bag rolled up and packed in vagina.

\begin{tabular}{lccc}
\hline \multicolumn{2}{l}{ Device inserted 30 year back } & Device inserted 26 years & Device inserted 17 years back \\
\hline Age & 70 & 71 & 67 \\
Widow & yes & yes & No \\
Parity & 11 & P7+1 & 4 \\
\hline
\end{tabular}

Parity at prolapse $5 \quad$ Parity at prolapse $1 \quad$ Parity at prolapse 1

1. Women who had knowledge about the possibility of treatment and approached surgical facility, as they have money to afford appropriate treatment.

2. Women, who had some idea about the available treatment, facility at least for insertion of vaginal ring pessary.

3. Third category of women, who were very similar to that of our case in discussion, who are shy and do not like to tell any one about their problem and have participated themselves in making their own device.

4. The last group of women those who were economically incapable to or rather poor and did not mind dying with prolapse.

As mention above, vaginal ring pessary has been useful for prolapse. ${ }^{1}$ However the neglected ones have given urinary and rectal fistulas. ${ }^{2,3}$

Today, in modern Nepal, women with prolapse are helped out by young Gynecologists. Innumerable surgeries have taken place in the last five years.A fast tract vaginal surgery for pelvic floor repair has been described in resourceful setting quite unlike ours too. ${ }^{4}$

\section{Conclusion}

Neglected self made (home) made devices generating offensive smell worn for more than decade for pelvic organ prolapse by Nepalese women speaks of the health status in yester years now getting better by increased number of Gynecological Surgeons in the country who are very eager to improve women's health status by reaching to the community.

\section{References}

1. Singh K, Reid WM. Non-surgical treatment of uterovaginal prolapse using double vaginal rings. BJOG 2001 Jan; 108(1):112-3.

2. Powers K, Grigorescu B, Lazarou G, Greston WM, Weber T. Neglected pessary causing a rectovaginal fistula: a case report. J Reprod Med 2008 Mar; 53(3):235-7.

3. Kaaki B, Mahajan ST. Vesicovaginal fistula resulting from a well-cared-for pessary. Int Urogynecol J Pelvic Floor Dysfunct 2007 Aug; 18(8):971-3.

4. Ottesen M, Sørensen M, Rasmussen Y, SmidtJensen S, Kehlet H, Ottesen B. Acta Obstet Gynecol Scand. Fast track vaginal surgery. 2002 Feb; 81(2):138-46. 